\title{
METABOLISM, TOXICITY AND MANNER OF ACTION OF GOLD COMPOUNDS \\ USED IN THE TREATMENT OF ARTHRITIS. I. HUMAN PLASMA AND \\ SYNOVIAL FLUID CONCENTRATION AND URINARY EXCRETION \\ OF GOLD DURING AND FOLLOWING TREATMENT WITH \\ GOLD SODIUM THIOMALATE, GOLD SODIUM THIO- SULFATE, AND COLLOIDAL GOLD SULFIDE
}

\author{
By R. H. FREYBERG, WALTER D. BLOCK, AND S. LEVEY \\ (From the Rackham Arthritis Research Unit, ${ }^{1}$ the Medical School, University of Michigan, \\ Ann Arbor)
}

(Received for publication March 24, 1941)

There has been increasing interest in the use of gold salts in the treatment of arthritis since the favorable report of Forestier (1) in 1929. Numerous reports from various parts of the world emphasize the value of this form of treatment, especially for rheumatoid arthritis; in many instances it is stated that gold therapy has been found more beneficial than any other treatment. In the United States this treatment has become popular only in the past three years, stimulated largely by the endorsement of Key (2).

In 1938 we began a critical clinical study of this form of therapy in cases of typical rheumatoid arthritis, using gold sodium thiomalate (myochrysine) and gold sodium thiosulfate. At the end of a year's trial, our experience led us to the following temporary conclusions: (1) gold therapy is definitely beneficial to some but not all patients with rheumatoid arthritis during the active inflammatory stage of the disease and (2) the treatment frequently produces toxic reactions, many of which may be serious. We were convinced of the potential value of this form of therapy, and equally convinced that this method of treatment was quite unsatisfactory in its existent state.

Treatment of arthritis with gold salts originated and to date largely remains on an empirical basis. We have been unable to discover any scientific basis (1) for the selection of the various gold salts commonly used, (2) for the popularity of the parenteral route of administration, (3) for determining the size of the individual doses and the total amount of the drug which will be given, and (4) for deciding upon the interval between

1 The Rackham Arthritis Research Unit is supported by the Horace H. Rackham School of Graduate Studies of the University of Michigan. doses and courses of treatment. Clinical experience has led to certain preferences, many of which are conflicting. The method of action of gold salts to produce benefit or toxic reactions is not known. The literature contains very little information concerning the metabolism of gold or the fate of this element when administered in the treatment of arthritis. Methods employed in the previous studies of this subject are for the most part non-specific and lack sufficient sensitivity to give reliable results.

For these reasons, we began an intensive study of this problem with the belief that information could be obtained on the basis of which the value and limitations of gold therapy might be clearly defined; if the value of gold therapy was upheld, it was hoped that the administration of preparations of gold now available, or others that might be developed, could be put on a scientific basis so that by adequate laboratory control maximum benefit would be accomplished and toxic reactions would be avoided entirely or minimized.

We adopted the premise that the effects of gold salts are due to gold contained in the molecule. Our purpose was to determine the fate of gold administered in different ways in the treatment of patients with rheumatoid arthritis. In this first report results obtained with the use of gold sodium thiomalate, ${ }^{2}$ gold sodium thiosulfate, ${ }^{3}$ and colloidal gold sulfide ${ }^{4}$ will be presented. The first two preparations, which are solutions of crystalline gold salts, were investigated because they

${ }^{2}$ Myochrysine, marketed by Merck \& Co., Rahway, New Jersey.

${ }^{3}$ Supplied for this study by G. D. Searle \& Company, Chicago, Illinois.

4 Aurol-Sulfide, supplied for this study by Hille Laboratories, Chicago, Illinois. 
are used more extensively than other gold compounds in this country; colloidal gold sulfide was studied in order to compare the behavior of a colloidal suspension of a gold salt with the solutions of crystalline gold compounds, and also because it could be administered orally, intravenously or intramuscularly.

\section{METHODS}

Patients who had typical rheumatoid arthritis with active joint synovitis were studied during treatment and for many months following treatment. In most instances gold sodium thiomalate, gold sodium thiosulfate and colloidal gold sulfide were injected intramuscularly; in some cases colloidal gold sulfide was administered orally entirely, in other cases it was given orally and also intramuscularly. Injections were made weekly except in rare instances when they were at five-day intervals. Salicylates and, in some cases, small doses of vitamins $C$ and $\mathrm{D}$ and hypnotics were the only other drugs used during these investigations.

In some patients extensive, continuous metabolism studies were conducted similar to those commonly employed in the study of calcium and phosphorus. During the period of administration of increasing doses of the drug, and for two or three weeks after a fixed weekly dose was given, twenty-four hourly collections of urine were analyzed for gold by the method of Block and Buchanan (3). Creatinine determinations were made by the method of Folin (4) to check the complete collection of urine. The content of gold was determined in venous blood plasma obtained at the same time in the morning, usually daily. (Fecal gold was not determined during the investigation reported in this communication.)

In many other patients, twenty-four hourly collections of urine and samples of venous blood were analyzed for gold at intervals during and after treatment with gold salts. Gold analyses were made of knee joint fluid and blood obtained simultaneously from some patients. Often plasma and urine gold values were determined previous to administration, and at one, two, four, six and twentyfour hours after giving a gold salt (a method similar to a glucose tolerance test) in order to learn the speed of absorption of gold from intramuscular depots or the intestinal tract, and the resultant urinary excretion of gold.

The gold content of the compounds used during this study was frequently determined.

Since the amount of gold employed is small, the analytical method must be extremely sensitive, specific, and accurate. Among the available methods for gold analysis, we found none which was sufficiently specific and sensitive to be employed satisfactorily in the analysis of biological fluids and tissue. A photoelectric colorimetric micromethod was devised by Block and Buchanan (3) specifically for this work; this procedure has been highly satisfactory and has been employed in all of our investigations.

\section{RESULTS}

Samples of blood and urine obtained from patients who were not treated with gold compounds, and from normal control subjects, never contained gold by our method of analysis. Since all the gold in blood was found to be present in the plasma, all analyses were made on plasma and are reported in terms of plasma concentration.

TABLE I

The gold present in plasma and synovial fluid obtained simultaneously from patients treated with gold sodium thiomalate and colloidal gold sulfide intramuscularly

\begin{tabular}{|c|c|c|c|c|}
\hline Patient & Preparation & $\begin{array}{l}\text { Weakly } \\
\text { intake } \\
\text { of gold }\end{array}$ & $\begin{array}{l}\text { Gold } \\
\text { in } \\
\text { plasma }\end{array}$ & $\begin{array}{l}\text { Gold in } \\
\text { oynovial } \\
\text { fluid }\end{array}$ \\
\hline T. W. & $\begin{array}{l}\text { Gold sodium thiomalate intramusoularly } \\
\text { (Myochrysine) }\end{array}$ & $\begin{array}{l}\text { mom. } \\
12.5\end{array}$ & $\begin{array}{c}\text { mom. } \\
\text { per cent } \\
0.03 \\
0.33\end{array}$ & $\begin{array}{l}\text { mom. } \\
\text { per cent } \\
0 \\
0\end{array}$ \\
\hline K. N. & $\begin{array}{l}\text { Gold sodium thiomalate intramuscularly } \\
\text { (Myochrysine) }\end{array}$ & 25 & $0.42^{*}$ & $0.43^{*}$ \\
\hline F. $\mathbf{M}$ & $\begin{array}{l}\text { Gold sodium thiomalate intramuscularby } \\
\text { (Myochrysine) }\end{array}$ & 25 & $\begin{array}{l}0.16 \\
0.59^{*}\end{array}$ & 0.11 \\
\hline L. W. & $\begin{array}{l}\text { Gold sodium thiomalate intramuscularly } \\
\text { (Myochrysine) }\end{array}$ & 50 & 0.25 & 0.24 \\
\hline O. J. & $\begin{array}{l}\text { Gold sodium thiomalate intramuscularly } \\
\text { (Myochrysine) }\end{array}$ & 50 & $0.07 \dagger$ & $0 \dagger$ \\
\hline \multirow[t]{2}{*}{ C. $\mathbf{K}$. } & Colloidal gold sulfide intramuscularly & 15 & $\begin{array}{l}0.07 \\
0.19^{*}\end{array}$ & $\begin{array}{l}0 \\
0^{*}\end{array}$ \\
\hline & & & $\begin{array}{l}0 \\
0.20 *\end{array}$ & $\begin{array}{l}0 \\
0.21^{*}\end{array}$ \\
\hline S. C. & Colloidal gold sulfide intramuscularly & 43 & $\begin{array}{l}0.18 \\
0.08\end{array}$ & $\begin{array}{l}0.11 \\
0.03\end{array}$ \\
\hline F. S. & Colloidal gold sulfide intramuscularly & 60 & 0.04 & 0.05 \\
\hline
\end{tabular}

* Four hours after injection.

$\dagger$ Ten months after last injection.

Results obtained in subject M. B. (Figure 1) are characteristic of those obtained in three other persons treated with gold sodium thiomalate and given increasing amounts supplying from 10 to 50 mgm. of gold, until $500 \mathrm{mgm}$. of gold had been administered. It should be particularly noted that, throughout this study, dosage is referred to in terms of the gold and not the quantity of the gold salt; in this way the gold administered in the different drugs can be readily compared. ${ }^{5}$

Gold was found in the blood in increasing amounts as the amount of gold injected increased. Between injections, the daily plasma values fluctuated somewhat but, in general, after each injec-

5 The dose of the drug can be readily computed; gold sodium thiomalate is 50 per cent gold by weight, gold sodium thiosulfate is 37 per cent gold, and colloidal gold sulfide is 87 per cent gold. 
GOLD IN PLASMA AND URINE

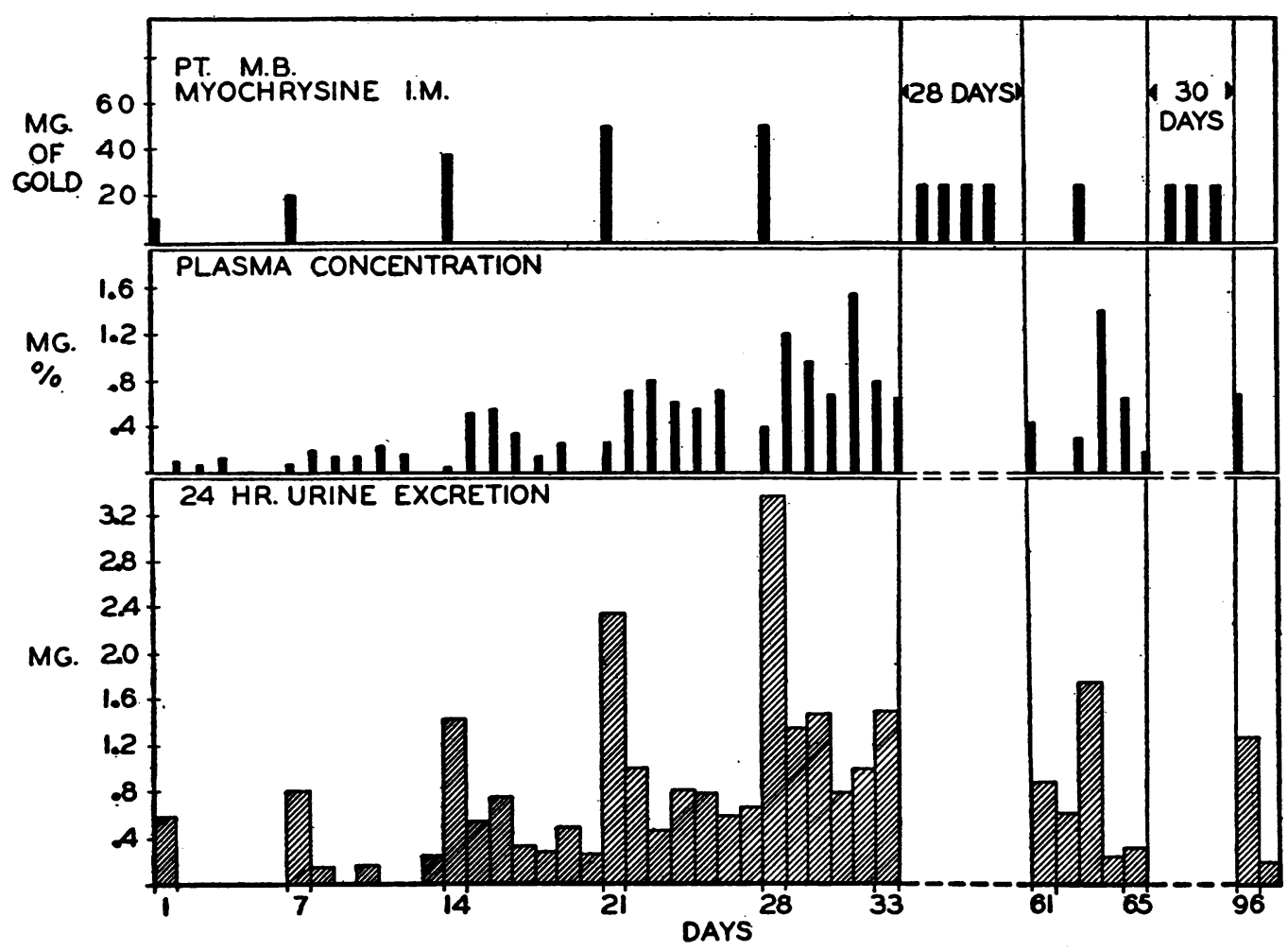

Fig. 1. Plasma Concentration and the Excretion of Gold in the Urine of a Patient With Rheumatoid Arthritis Treated With Gold Sodium Thiomalate (Myochrysine) Injected INTRAMUSCULARLY AT WEEkLY INTERVALS

Increasing doses were employed until two doses containing $50 \mathrm{mgm}$. of gold were given; thereafter, $25 \mathrm{mgm}$. of gold were injected.

tion the plasma gold concentration increased and either remained at this higher level or decreased slightly until the next injection was given. The plasma concentration after the first injection of $50 \mathrm{mgm}$. of gold (between the twenty-first and twenty-eighth days) averaged about $0.8 \mathrm{mgm}$. per cent. Subsequently, after weekly injections of 25 mgm. of gold, the average plasma content was less; it did not increase as more gold was administered. Similarly, the excretion of gold in the urine increased as larger amounts of gold were injected; the increased excretion, however, was not directly proportional to the increased administration of gold. Although fecal analyses were not done in the study of this patient, in others we have found that the urine is the chief route of excretion of gold administered in this compound. Thus it is seen that gold is being retained in the body in increasing amounts as the size of the injection is increased. This apparent retention of gold is of important magnitude; for instance, after $50 \mathrm{mgm}$. of gold were injected on the twenty-first day, an average of only $1 \mathrm{mgm}$. was excreted daily during the following week, so that only $7 \mathrm{mgm}$. of the $50 \mathrm{mgm}$. of gold injected (14 per cent) were eliminated in the urine before another 50 mgm. were injected on the twenty-eighth day. Thus one needs to account for the remaining 86 per cent of gold. In this connection, the finding of significant plasma concentrations and continued urinary excretion of gold long after its administration ceased, as will be demonstrated later (Figures 7 and 8), is extremely interesting. The excretion of gold did not increase after the amount of gold injected was no longer increased; the excretion was definitely less after the weekly dose of 


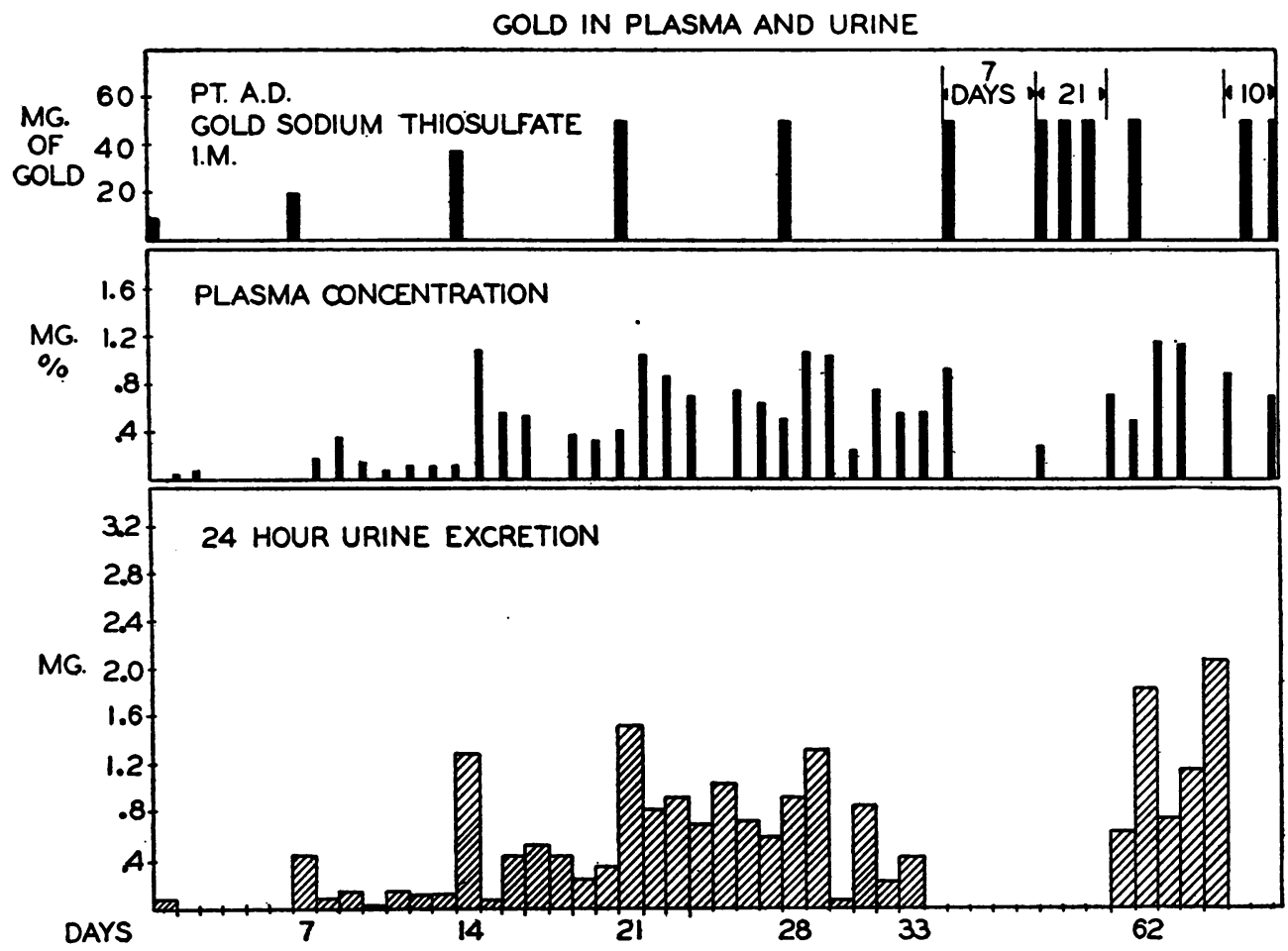

Fig. 2. Plasma Concentration and Excretion of Gold in the Urine of a Patient With Rheumatoid Arthritis Treated With Gold Sodium Thiosulfate, Injected Intramuscularly at WeEkLy Intervals

Increasing doses were employed until the dose contained $50 \mathrm{mgm}$. of gold, at which level it remained throughout the remainder of the study.

gold was reduced to $25 \mathrm{mgm}$. (Compare sixtyfirst to sixty-fifth days with twenty-first to thirtythird days.) Without exception the excretion of gold was much greater on the day of injection than on other days. These high urine values on the day of injection were quite likely the result of the quick rise in plasma concentration after injection (Figure 4); however, the excretion decreases more quickly and to a greater degree than does the plasma gold content.

Findings in the case of A. D. (Figure 2) are characteristic of the results obtained when gold sodium thiosulfate was given in precisely the same way and in doses providing equivalent amounts of gold, except that after the dose was increased to an amount containing $50 \mathrm{mgm}$. of gold it was kept at this level thereafter. In general, the plasma and urine gold values are strikingly similar to those obtained with gold sodium thiomalate. The urinary excretion of gold on the day of injection was greater than on subsequent days, but usu- ally less than occurred when gold sodium thiomalate was administered. With this drug, as with gold sodium thiomalate, the plasma and urine values did not increase after the weekly dose was no longer increased, even though gold was being retained throughout the course of treatment.

Results obtained with colloidal gold sulfide were exceedingly variable. Findings in M. R., the first patient studied extensively while this drug was employed, appear in Figure 3. Colloidal gold sulfide was administered daily in amounts providing $182 \mathrm{mgm}$. of gold per week, which was much more than was given either as gold sodium thiomalate or as gold sodium thiosulfate. This patient absorbed gold both from the intestinal tract and from muscle depots when it was administered in this colloidal form. The concentration of gold in blood obtained usually every day (before treatment was given that day) varied somewhat from day to day; the average was slightly higher when it was given orally three times a day than when 
COLD IN PLASMA AND URINE
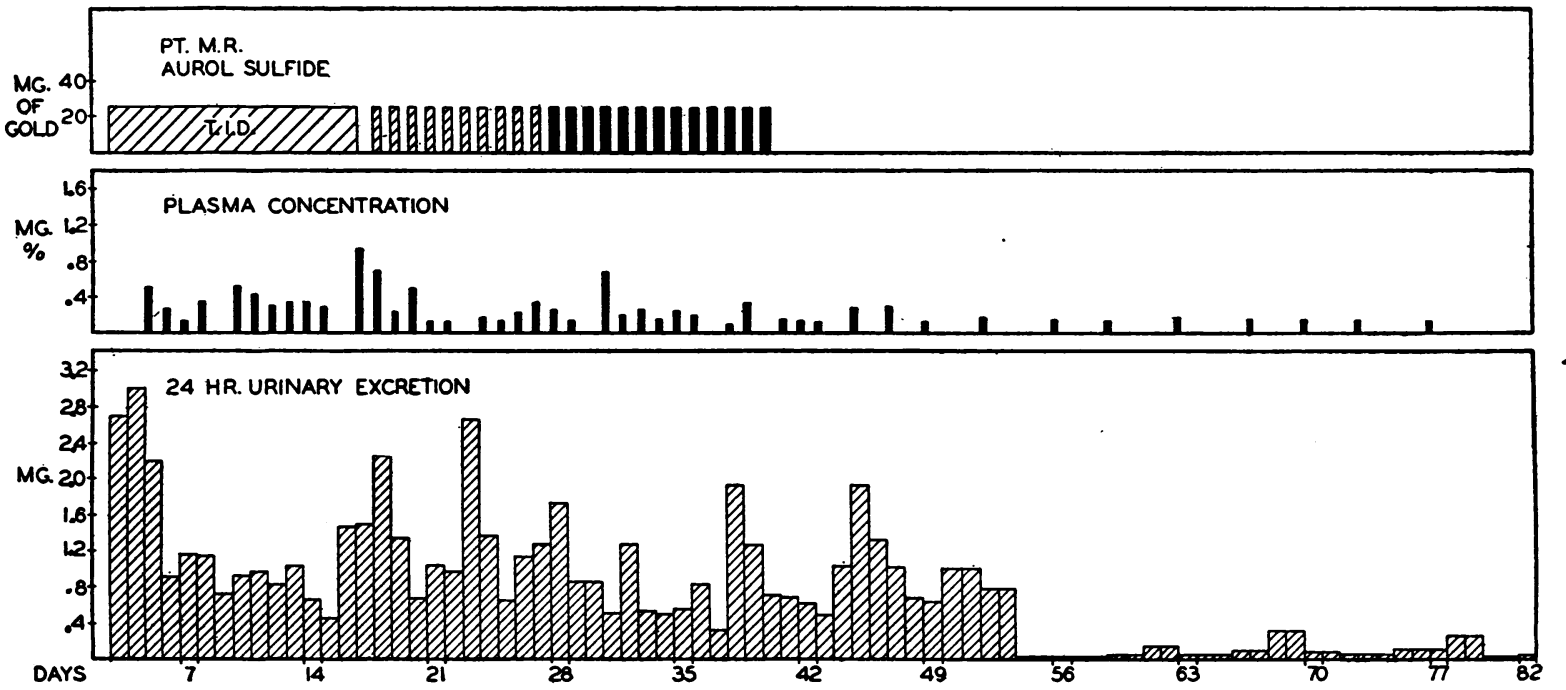

Fig. 3. Plasma and Urine Values in a Patient with Rheumatoid Arthritis Treated with Colloidal

Gold SUlFide

During the first sixteen days $8.7 \mathrm{mgm}$. of gold were given orally three times daily; from the seventeenth through the twenty-seventh day the drug was given orally in a single morning dose equivalent to the total daily dose during the previous period; beginning with the twenty-eighth day this same daily dose was injected intramuscularly.

it was given in a single morning dose. There was no difference in plasma concentration whether the drug was ingested or injected. Except for the first few days when the urine content was unexplainably higher, the average excretion of gold in urine was about $1 \mathrm{mgm}$. daily. Thus with a larger intake of gold given as colloidal gold sulfide, the gold concentration of the plasma was significantly lower and the excretion of gold was about the same as when only $50 \mathrm{mgm}$. of gold were injected intramuscularly as a true aqueous solution of either gold sodium thiomalate or gold sodium thiosulfate. A significant blood and urine content of gold existed for six weeks after the last administration of gold sulfide. The studies ceased at this time; how much longer gold would have been found in the blood and urine of this patient we do not know.

It should be emphasized that the findings in this patient (M. R.) are not characteristic of others treated with colloidal gold sulfide, but rather the exception, in that both the plasma and urine content of gold was much higher in this patient than in most others studied. This will be emphasized again when average values obtained with different gold compounds are contrasted (Table II). The findings in this case (M. R.) show that some persons do absorb gold from the intestinal tract and from muscle depots when colloidal gold sulfide is administered. In some patients similarly treated no gold was found in the blood or urine; in most subjects studied there was considerable variation in the values, but with rare exceptions the values in both blood and urine were much lower than were found in M. $R$.

TABLE II

The average plasma and urine gold values obtained from analyses of many specimens from many different patients during the latter part of treatment with gold sodium thiomalate, gold sodium thiosulfate and colloidal gold sulfide.

The values for the combined oral and intramuscular administration of gold sulfide are averages of analyses in only one patient.

\begin{tabular}{|c|c|c|c|c|}
\hline Preparation & Route of administration & $\begin{array}{c}\text { Average } \\
\text { weekly } \\
\text { intake } \\
\text { of } \\
\text { gold }\end{array}$ & $\begin{array}{c}\text { Gold } \\
\text { in } \\
\text { plasma }\end{array}$ & $\begin{array}{c}\text { Gold in } \\
\text { urine } \\
\text { (twenty- } \\
\text { four } \\
\text { hourly } \\
\text { excre- } \\
\text { tion) }\end{array}$ \\
\hline & & mom. & $\underset{\text { per cent }}{\text { mom. }}$ & mgm. \\
\hline $\begin{array}{l}\text { Gold sodium thiomalate } \\
\text { (Myochrysine) }\end{array}$ & Intramuscularly & $\begin{array}{l}50 \\
25 \\
12.5\end{array}$ & $\begin{array}{l}0.44 \\
0.33 \\
0.26\end{array}$ & $\begin{array}{l}0.75 \\
0.63 \\
0.23\end{array}$ \\
\hline Gold sodium thiosulfate & Intramuscularly & $\begin{array}{l}37.4 \\
19\end{array}$ & $\begin{array}{l}0.45 \\
0.28\end{array}$ & $\begin{array}{l}0.98 \\
0.43\end{array}$ \\
\hline \multirow[t]{3}{*}{ Colloidal gold sulfide } & Orally & 60 & 0.07 & 0.21 \\
\hline & Orally and intramuscularly & 140 & 0.01 & 0 \\
\hline & Intramuscularly & 43 & 0.18 & 0.18 \\
\hline
\end{tabular}




\section{TWENTY-FOUR HOURLY PERIODS FOLLOWING INUECTION}
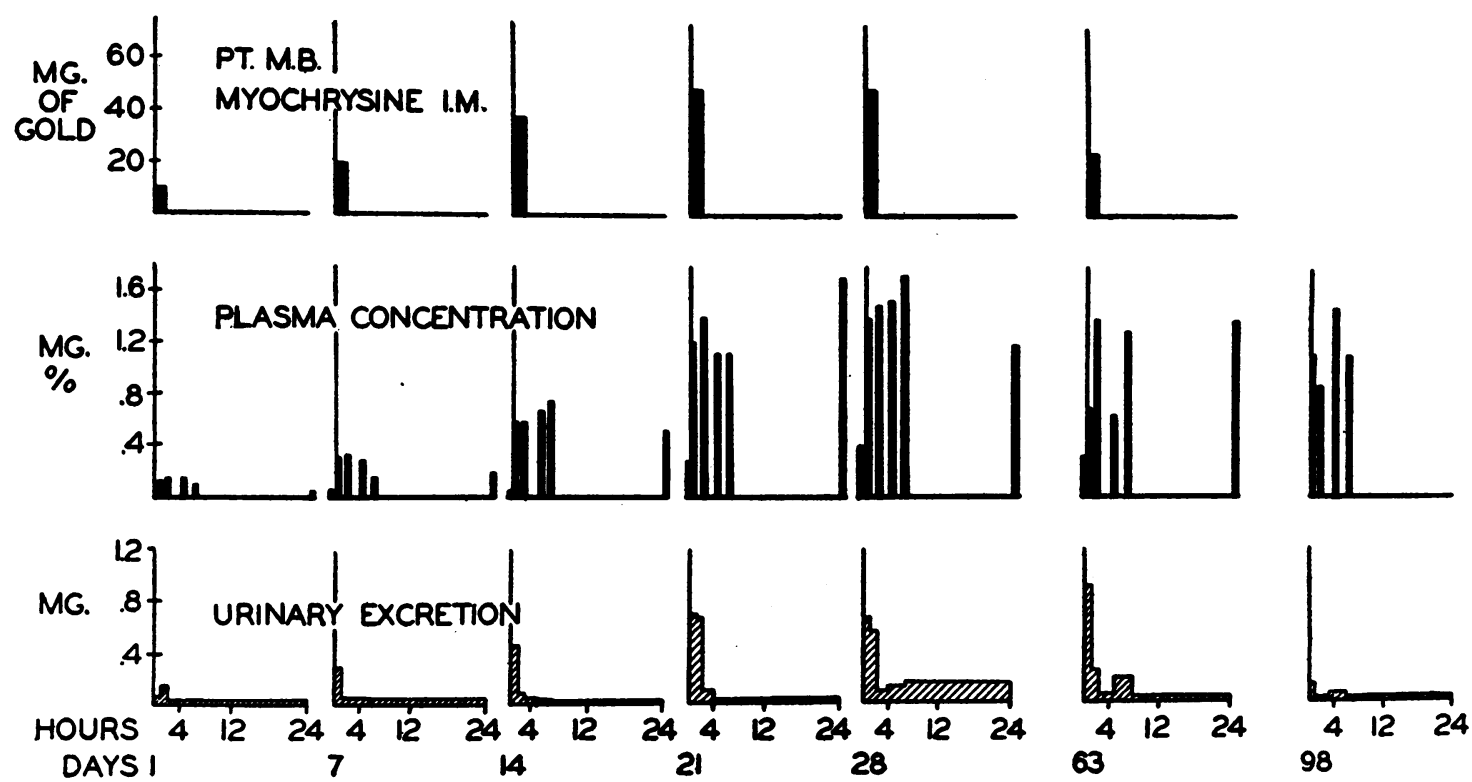

Fig. 4. Plasma Content of Gold Before the Intramuscular Injection of Gold Sodium Thiomalate and One, Two, Four, Six and Twenty-four Hours After; and Gold Content of the Urine Formed BrtWeen the Time of the BloOd Analyses

The vertical lines extending through the graph indicate the time of injection. The plasma values just preceding each line represent the blood gold concentrations just before each injection. Urine values for periods longer than one hour are average hourly values determined from urine accumulating between times of plasma determinations. Only the days of injection are shown; the intervening six-day periods are indicated by interruptions in the base lines. On the ninety-eighth day no gold salt was injected but the plasma and urine were analyzed as on previous injection days.

Information concerning the absorption into the blood stream, disappearance from the blood, and the urinary excretion of gold was obtained by analyses of plasma and urine during the first few hours after administration of a gold salt. In Figures 4, 5, and 6 are the results of such studies made in the same patients whose daily findings appear in Figures 1,2 and 3. In every instance, one hour after the injection of gold sodium thiomalate (Figure 4) the plasma contained a much greater amount of gold than was present just before injection, and the plasma content was higher as the amount of gold injected was increased. Subsequent analyses during the twentyfour-hour period showed plasma values essentially the same as obtained one hour after injection. Thus there was no quick fall in plasma gold content after the intramuscular injection of gold sodium thiomalate. The urine formed during the first hour after injection usually contained more gold than in subsequent hours. There was little correlation between urine and plasma values; for example, on the twenty-first and also on the twenty-eighth day the urinary excretion of gold decreased during the twenty-four-hour period after injection, while the plasma values remained almost constant.

Results obtained with gold sodium thiosulfate (Figure 5) were almost identical to those found with gold sodium thiomalate, except that the urine values were smaller and the excretion was slower.

The plasma contained different amounts of gold at different hours in a twenty-four-hour period when colloidal gold sulfide was given orally in equal doses three times daily (Figure 6). This may have been the result of an inconstant rate of absorption from the intestinal tract or an inconstant rate of removal from the blood. On the days when gold sulfide was given in a single morning dose, the plasma content was more con- 


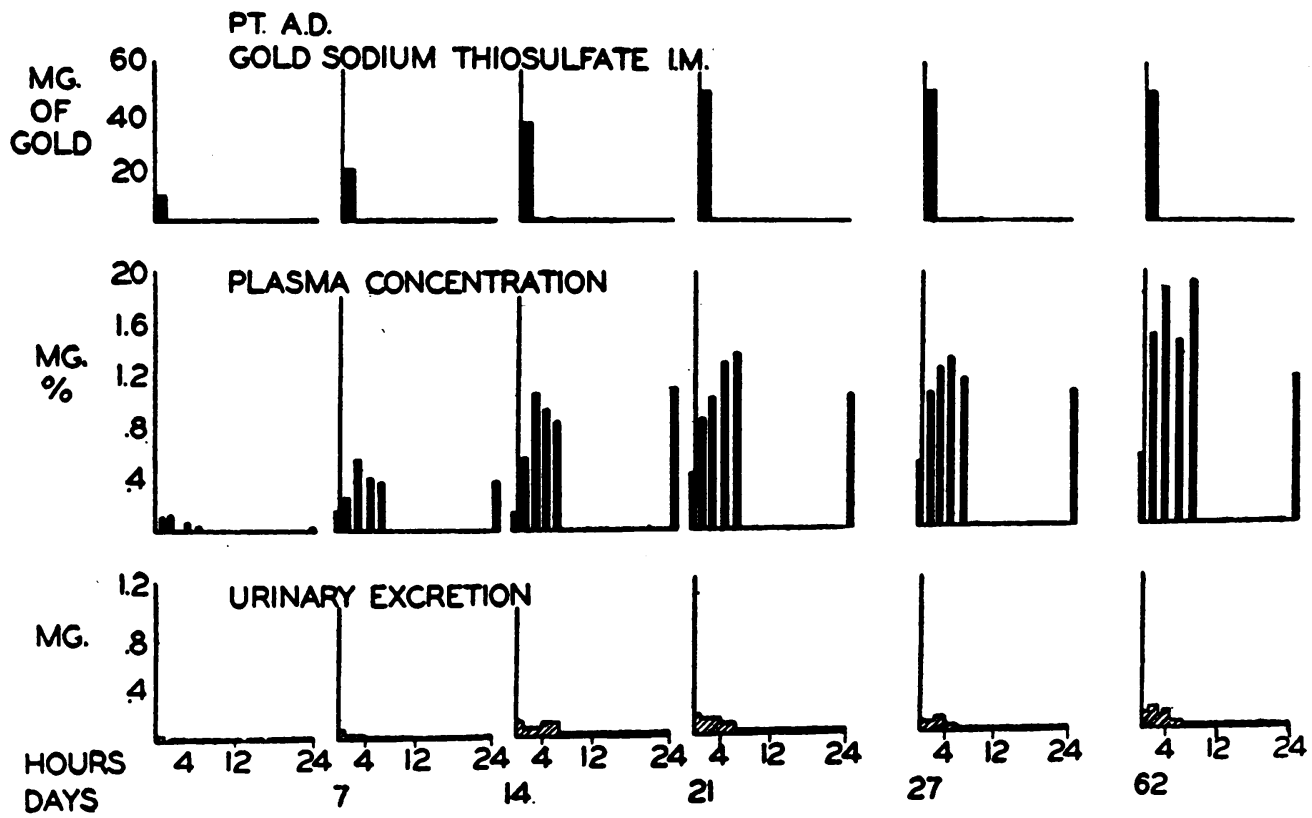

Fig. 5. Plasma Content of Gold Before the Intramuscular Injection of Gold Sodium Thiosulfate, and One, Two, Four, Six and Twenty-rour Hours After; and the Gold Content of the Urine Formed Between the Time of Blood Analyses

The injections are indicated by the vertical lines extending through the graph. Plasma values shown just before these lines represent the blood gold concentration just before the injections. Urine values for periods longer than one hour are average hourly values.

stant; there was no significant difference whether the salt was given orally or intramuscularly. Excretion of gold was greater during the first two hours after administration than subsequently. Again it must be emphasized that the findings in this case are not characteristic of others treated with this preparation of gold, most of whom had much lower plasma and urine values.

Comparison of plasma and synovial fluid gold content of specimens obtained simultaneously can be made from the data in Table I. In some patients plasma and synovial fluid values were almost identical, in others the joint fluid contained less gold than did the plasma, in still others no gold was found in the synovial fluid. Gold quickly diffused into the joint space in some instances, as results indicate in $\mathrm{K}$. N. and the last value obtained in C. K. (In each case analyses were made four hours after an injection of gold.) This was not true in other cases. The presence of a small amount of gold in plasma and none in the joint fluid of O. J. ten months after the administration of gold ceased indicates that gold did not remain in synovial fluid longer than in the plasma. Synovial fluid concentration was never significantly higher than the plasma concentration. Differences in synovial fluid gold content, as compared to plasma content, observed in different patients may very well be due to structural variation and permeability in synovium and joint capsule as a result of differences in degree of inflammation and duration of the disease.

The three gold salts employed in this investigation can be compared further by studying the average values of many analyses of blood and urine obtained to date from many different patients during the latter part of a course of treatment (Table II). ${ }^{\circ}$ Plasma and urine values were higher when larger amounts of gold were admin-

- As more data are accumulated with subsequent study, these averages may change. 


\section{TWENTY-FOUR HOURLY PERIODS FOLLOWING ADMINISTRATION}
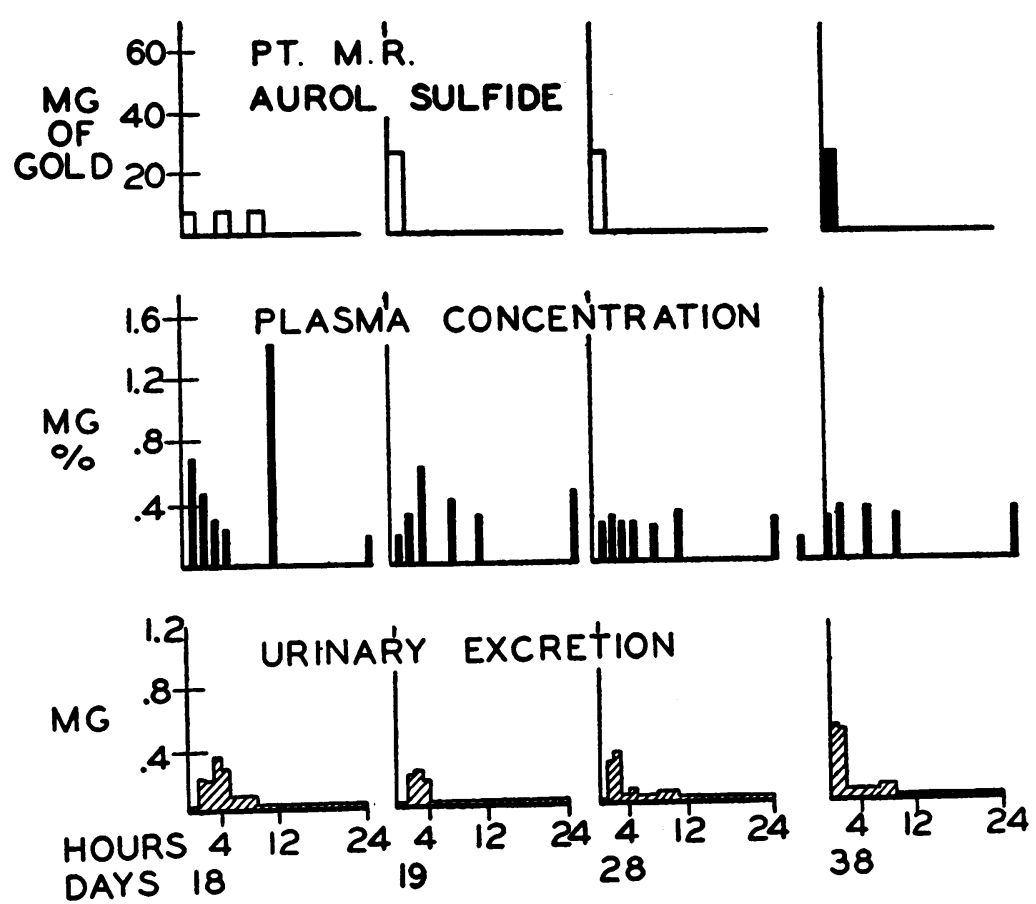

Fig. 6. Plasma Concentration of Gold Determined at Short Intervals After the Oral and Intramuscular Administration of Colloidal Gold SULFIDE

On the eighteenth day three equal doses, each supplying $8.7 \mathrm{mgm}$. of gold, were given orally; on the nineteenth and twenty-eighth days $26.1 \mathrm{mgm}$. of gold were given in a single morning dose orally, and on the thirty-eighth day, the same dose was injected intramuscularly. Urine values for periods longer than one hour are hourly averages.

istered either as gold sodium thiomalate or gold sodium thiosulfate, but they were not proportional to the weekly intake of gold. Average plasma and urine values were comparable when similar amounts of gold were given as the sodium thiomalate or sodium thiosulfate salt (both crystalline). These data also show the small amount of gold that was eliminated in the urine during the period of administration of these salts. Very different results were obtained with colloidal gold sulfide; the average values in plasma and urine were very small, even though much more gold was given than when the crystalline preparations were used. The route of administration of the gold sulfide was not a significant factor.

One of the most important results of this investigation was the finding of significant amounts of gold in the blood and urine for a long time after the administration of gold salts had ceased. A typical example of this appears in Figure 7. This patient was treated with gold sodium thiomalate in the manner commonly employed, i.e., she was given intramuscular injections of this drug beginning with an amount which contained $10 \mathrm{mgm}$. of gold and increased until $50 \mathrm{mgm}$. of gold were injected. This dose was given weekly until the patient had received over $500 \mathrm{mgm}$. of gold (1010 mgm. of the drug). Plasma contained gold each time an analysis was made throughout the first thirteen weeks after the last injection, and the urine contained gold for sixteen weeks after treatment stopped. Similar results were always obtained in the many patients studied.

The length of time gold was found in plasma 

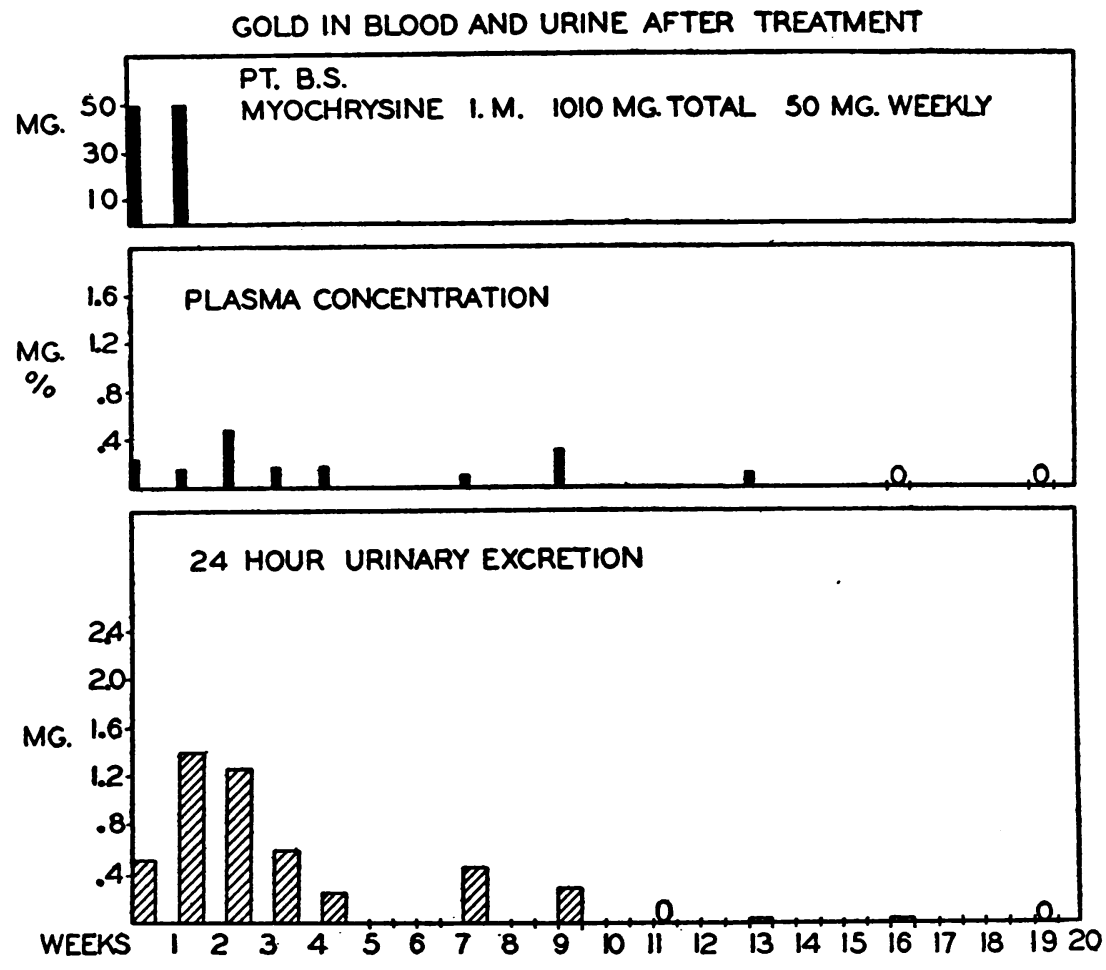

Fig. 7. Showing the Long Period After Treatment with Gold Sodium Thiomalate (Myochrysine) During Which Gold Was Found in Significant Amounts in Plasma and Twenty-four Hourly Urine Collections

After initial increasing doses of the drug, $50 \mathrm{mgm}$. of gold (100 mgm. of the salt) were injected at weekly intervals until $1010 \mathrm{mgm}$. of the salt had been given. The last two injections and the corresponding plasma and urine values are shown.

is correlated with the size of the weekly doses of gold sodium thiomalate in Figure 8 . In the case of those patients who received $50 \mathrm{mgm}$. of gold weekly, the earliest the urine was found to contain no gold was six months after the last injection. Some patients were excreting gold seven, nine, and ten months after treatment ended. The urine of three patients given weekly injections of $25 \mathrm{mgm}$. of gold was negative three months after the last injection. One of two patients who received $12.5 \mathrm{mgm}$. of gold weekly until $160 \mathrm{mgm}$. had been given excreted no gold in the urine one month after the last injection. Although these observations are not completed, these data indicate that the excretion of gold continues for a long time after administration of gold is stopped, and that the length of time is approximately proportional to the size of the weekly dose. It seems very significant, too, that five of the six persons who received large weekly doses of gold (Figure
8) had significant toxic reactions (lingering generalized exfoliative dermatitis, nephritis, stomatitis and gastro-intestinal difficulties). None of the eight who received $25 \mathrm{mgm}$. of gold weekly had any evident toxic reaction to gold; one of the two patients receiving the smallest dose had purpura which disappeared ten days after the drug was stopped. Hence, serious toxicity seems to be definitely related to the amount of gold injected and the speed of administration.

The results of plasma analyses were similar to the findings shown in Figure 8, indicating that gold circulates in the body for a long time after its administration is stopped.

\section{DISCUSSION}

The data of this report are only the first results of an investigation of the metabolism, excretion and toxicity of gold in relation to its use in the treatment of rheumatoid arthritis. Consequently, 


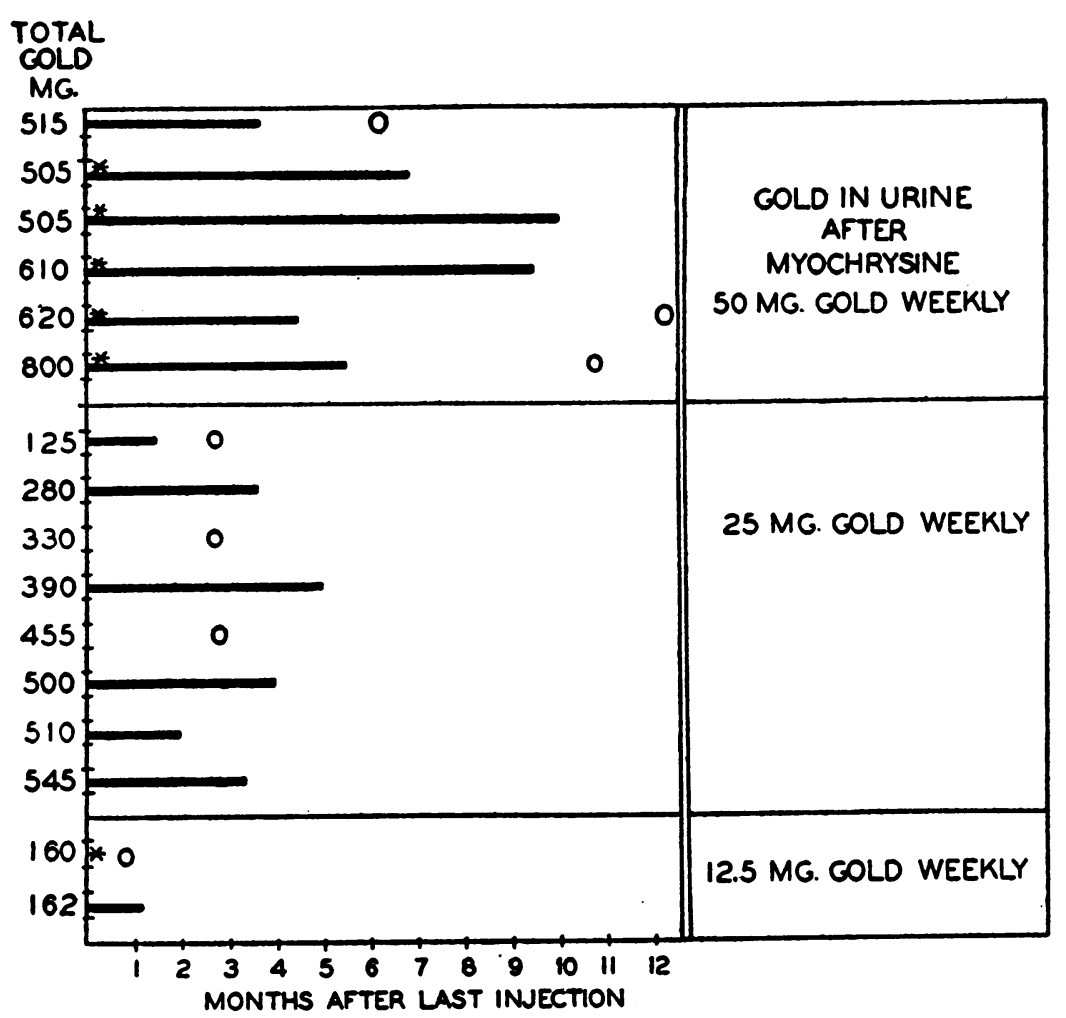

Fig. 8. Showing the Length of Time After Treatment With Gold Sodium Thiomalate That Gold Was Found in Urine, Correlated With the Size OF THE WeEkLy Dose

Each line represents a different patient and is extended to the time of the last analysis showing gold. When an analysis showed no gold, a zero is placed at the time that the analysis was made. An asterisk represents a significant toxic reaction to gold.

few conclusions can be drawn; at the same time these results indicate the nature of some interesting and valuable information which will undoubtedly be obtained as the investigation proceeds. Already certain facts are evident, and similarities of some gold medications and differences in others are clearly shown.

Gold sodium thiomalate and gold sodium thiosulfate are crystalline compounds which have similar solubilities and physical properties, and the metabolism of gold when injected intramuscularly in an aqueous solution of either of these two salts is similar. ${ }^{7}$ The plasma and urine gold values are much alike for each of these salts and, although variations occur, the results are much more uni-

7 Animal investigations now being conducted further emphasize the similarities in the metabolism of these two gold salts. form than are obtained with colloidal gold sulfide. The lower values commonly found after the oral and intramuscular administration of colloid gold sulfide may be due to slower or less complete absorption into the blood. They may, however, be the result of very quick removal of gold from the blood and its fixation in certain tissue. We are at present studying the effects of the intravenous injection of this colloidal gold salt. These investigations correlated with animal studies that are in progress are expected to add much information. The lower toxicity reported for this colloidal gold preparation (which we are observing) seems quite clearly to be related to the lower blood gold concentration and lower urinary excretion of gold given in this form. Similarly, if benefit from this preparation depends upon the circulation of a certain minimal amount of gold for a minimal length 
of time, therapeutic failures are to be expected in those persons whose plasma gold values are very small or zero. These problems are being investigated further.

The retention of gold during treatment and the prolonged excretion of gold after the intramuscular injection of gold sodium thiomalate and gold sodium thiosulfate readily explain the slowly developing, but long-maintained apparent benefit of gold therapy commonly observed. Similarly, toxic reactions usually reflected as damage to the skin, kidneys, liver and intestinal tract, which so often appear late in the course of treatment or even follow treatment by the conventional method of injecting these salts at weekly intervals in amounts providing $50 \mathrm{mgm}$. or more of gold, seem, in the light of our results thus far, to be due to the increasing retention of gold until it accumulates in amounts sufficient to damage these tissues. When such large doses of gold are given at frequent intervals, significant retention of gold may result due to its slow excretion, so that for many weeks its damaging effects continue, thus causing serious illness which may end fatally.

The toxic reactions to gold which we have encountered to date are of at least two kinds. Most commonly, reactions have occurred late in the course of treatment; these develop slowly and persist for many weeks. These toxic reactions are manifested chiefly as generalized dermatitis which sometimes becomes exfoliative; in fewer instances, they are manifested as nephritis. Thus far we have encountered such reactions only in patients who received many large weekly doses of gold (approximately $50 \mathrm{mgm}$.). It is our opinion that such reactions result from protoplasmic poisoning effects of accumulated amounts of gold and we believe they can be eliminated, or at least shortened in duration, by avoiding large, frequent doses and thus preventing a large retention of gold. Another type of reaction, which has been observed to occur shortly after an injection of the drug (not necessarily a large dose), is manifested as apprehension, headache, flushed face and tightness in the throat, or as a purpuric dermatitis due to capillary damage. Such reactions are less common; they occur usually early in the course of treatment, and appear to be manifestations of true drug sensitivity and not due to protoplasmic, heavy metal poisoning. Prevention of such reactions will quite naturally depend on measures unrelated to metabolic and excretory considerations.

In these studies, gold salts were given parenterally only by intramuscular injection. The blood concentration of gold will naturally depend upon the balance between the speed and duration of absorption of gold into the circulation and the rate of its removal from the blood into the tissues or for excretion. Gold is absorbed and found in the blood soon after intramuscular injection; for how long absorption from muscle depots continues and how completely, these studies do not indicate. The importance of the absorption of gold is being investigated further in humans by studying intravenously-injected gold preparations. Complete excretion studies are also being made, including daily analyses of feces for gold. Animal studies are being conducted to learn the sites of the deposition of gold in tissues.

The manner in which gold salts might produce benefit, and the site of such action, are complete mysteries to us. One naturally wonders whether gold acts in some beneficial way at the inflamed joints. In this connection, it is interesting to note that gold was not concentrated in joint fluid nor did it remain in synovial fluid after it had disappeared from the blood.

If gold might be therapeutically effective when it is present in sufficient amounts in an active form in the body, and if it acts as a poison when present in excess of a certain amount, it seems reasonable that the quantitative determination of gold in plasma or in the urine might serve to regulate dosage and indicate the method of administration which would effect dependable and safe therapy. We are therefore studying this question with great interest, but much more data than are now available are required to prove or disprove this possibility.

\section{SUMMARY AND CONCLUSIONS}

An investigation of the metabolism, excretion, toxicity and manner of action of gold used in the treatment of rheumatoid arthritis is being conducted. In this communication, data concerning plasma and synovial fluid concentration of gold and the excretion of gold in the urine of patients treated with gold sodium thiomalate (myochrysine), gold sodium thiosulfate and colloidal gold sulfide are reported and their significance is dis- 
cussed. Although the studies are as yet incomplete, the following tentative conclusions are warranted.

Following the intramuscular or the oral administration of these gold salts, gold absorbed into the blood stream is transported in the plasma.

Gold sodium thiomalate and gold sodium thiosulfate injected intramuscularly in amounts supplying equivalent amounts of gold result in similar plasma gold concentrations and urinary excretion of gold; and the plasma and urine gold values vary with the size of the weekly dose but are not directly proportional to it. When colloidal gold sulfide is administered either orally or intramuscularly, the plasma and urine values vary greatly in different patients; some persons absorb gold and have plasma and urinary values comparable to those obtained with the other salts studied, but most patients have very low plasma gold concentrations and excrete little gold in the urine, even though colloidal gold sulfide is given in amounts providing much more gold than is supplied in the crystalline salts of gold studied. In some persons no gold was found in plasma or urine after colloidal gold sulfide was given in large amounts.

Gold is eliminated in the urine very slowly. Blood and urine contain gold in significant amounts for a long time after administration of gold; the length of time corresponds approximately to the size of the weekly dose of gold.

Toxic reactions were much more frequent in patients receiving larger weekly injections of gold sodium thiomalate or gold sodium thiosulfate. Considering this fact in the light of the metabolism data, it would appear that many toxic reactions result from retention of gold in amounts sufficient to poison the patient and that such toxicity can be prevented by giving smaller doses of gold. Our experience to date indicates that therapeutic results are quite as good with smaller doses of these gold salts as with the conventional larger doses.

Gold is not concentrated in synovial fluid; it is present in joint fluid in an amount equivalent to or less than exists in plasma.

It is hoped that with the further pursuit of these investigations gold therapy may be placed on a sound scientific basis and that, if its value is upheld, laboratory controlled methods of administration may be developed so that this therapy will become dependable and safe.

\section{BIBLIOGRAPHY}

1a. Forestier, J., L'Aurothérapie dans les Rheumatismes Chroniques. Bull. et mém. Soc. Méd. d'Hop. de Paris, 1929, 53, 323.

b. Idem, The treatment of rheumatoid arthritis with gold salts injections. Lancet, 1932, 1, 441.

2. Key, J. A., Rosenfeld, H., and Tjoflat, O. E., Gold therapy in proliferative (especially atrophic) arthritis. J. Bone and Jt. Surg., 1939, 21, 339.

3. Block, W. D., and Buchanan, O. H., The microdetermination of gold in biological fluids. J. Biol. Chem., 1940, 136, 379.

4. Folin, O., On the determination of creatinine and creatine in urine. J. Biol. Chem., 1914, 17, 469. 